\title{
Penggunaan Media Sosial Tinder dan Fenomena Pergaulan Bebas di Indonesia
}

\author{
Cervia Ferdiana, Eko Harry Susanto, Sisca Aulia \\ cerviaferdianaa@gmail.com,ekos@fikom.untar.ac.id,siscaa@fikom.untar.ac.id \\ Fakultas Ilmu Komunikasi Universitas Tarumanagara Jakarta
}

\begin{abstract}
Tinder is an online dating social media that is used by the majority of young people. The presence of Tinder at the moment, has an unconscious influence on daily life. The existence of Tinder can help someone to find a friend or life partner. However, now there is a phenomenon of the function of social media online dating that is misused by the public. The purpose of this study is to find out the shift in function of social media Tinder, the choice of social media Tinder as medium to find promiscuity friends, and an increase in promiscuity among young Indonesians using social media Tinder. This study is a qualitative study with phenomenological methods. Data collection techniques in this study were in-depth interviews, participant observation, literature and the online data article. The results of this study are that there is an increase in promiscuity among young people in Indonesia using social media dating online Tinder because the majority of Tinder users has an open mindset then has high curiosity of something that has never been felt, and last because the environmental factors that support the individual to enter promiscuity.
\end{abstract}

Keywords: dating apps, promiscuity indonesia youth, social media Tinder.

\begin{abstract}
Abstrak
Tinder merupakan media sosial kencan daring yang digunakan mayoritas kalangan anak muda. Media sosial kencan daring Tinder dapat membantu seseorang untuk menemukan teman ataupun pasangan hidup. Namun, kini muncul fenomena fungsi media sosial kencan daring Tinder yang disalahgunakan oleh masyarakat. Tujuan dari penelitian ini ingin mengetahui adanya pergeseran fungsi dari media sosial Tinder, pemilihan media sosial Tinder sebagai sarana untuk mencari teman pergaulan bebas, dan adanya peningkatan pergaulan bebas yang terdapat di kalangan anak muda Indonesia menggunakan media sosial Tinder. Penelitian ini merupakan penelitian kualitatif dengan metode fenomenologi. Teknik pengumpulan data berupa wawancara mendalam, observasi partisipan, studi pustaka dan juga penelusuran data secara daring. Hasil dari penelitian ini adalah terdapat adanya peningkatan pergaulan bebas di kalangan anak muda Indonesia dengan menggunakan media sosial kencan daring Tinder. Hal ini karena mayoritas pengguna Tinder mempunyai pemahaman atau pola pikir yang terbuka, rasa penasaran dan keingintahuan yang tinggi untuk mencoba sesuatu yang baru, dan faktor lingkungan yang mendukung individu untuk memasuki pergaulan bebas.
\end{abstract}

Kata Kunci: aplikasi kencan daring, media sosial Tinder, pergaulan bebas

\section{Pendahuluan}

Pada umumnya manusia merupakan makhluk sosial yang tidak dapat hidup dengan sendirinya dengan kata lain manusia selalu berkomunikasi dan saling ketergantungan antara satu dengan lainnya. Seiring dengan berkembangnya teknologi, penyampaian informasi menjadi cepat dan mudah didapatkan oleh semua orang tidak peduli seberapa jauh jarak dan letak tempat tinggal orang tersebut. Contoh 
berkembangannya teknologi dalam bidang komunikasi adalah dengan terciptanya media sosial.

Media sosial sendiri mempunyai beraneka ragam jenis dan fungsi. Terdapat media sosial yang digunakan penggunanya sebagai sarana informasi dan komunikasi dan ada juga media sosial yang digunakan untuk mencari pasangan hidup. Media sosial Tinder yang dikenal sebagai sarana untuk dapat bertemu dan berkenalan secara digital dengan orang lain dengan tujuan sebagai media berkencan atau pencarian jodoh.

Media sosial Tinder sendiri tidak jauh berbeda dengan media sosial pencarian jodoh lainnya seperti Tantan, Paktor, Beetalk, dan lain-lain. Media sosial Tinder (Nick Bilton dalam http://nytimes.com diunduh 12 September 2019) lahir pada tahun 2012 oleh Sean Rad, Jonathan Badeen dan Justin Mateen dan dapat diunduh melalui smartphone secara gratis baik di Google Play ataupun App Store. Para penggunanya dapat mempunyai akun di media sosial Tinder hanya dengan log in melalui nomor smartphone dan mereka sudah dapat menggunakannya.

Salah satu media sosial yang terkenal di berbagai media massa sebagai salah satu media sosial kencan terpopuler (http://kumparan.com diunduh 12 September 2019), berbagai fitur ditawarkan melalui media sosial Tinder baik secara gratis maupun berbayar. Fitur basis yang ada seperti swipe kanan, kiri dapat digunakan oleh para penggunanya sebagai filter ketertarikan seseorang berdasarkan foto dan deskripsi diri sedangkan untuk fitur berbayar pengguna akan mendapatkan fitur seperti mengetahui siapa saja yang menyukai kita dan unlimited likes.

Dengan hadirnya media sosial Tinder dalam kehidupan masyarakat sendiri ditanggapi dengan respon positif dan negatif. Di satu sisi Tinder dianggap dapat membantu masyarakat yang ingin serius mencari pasangan hidup (Yourdan dalam http://hipwee.com diunduh 15 September 2019), namun dan di sisi lain dapat memberikan pengaruh budaya yang berbeda masuk terhadap kehidupan dan tingkah laku seseorang. Budaya berbeda yang dimaksud oleh peneliti adalah pergaulan bebas yang mengarah ke free sex atau dikenal juga dengan istilah hookup, one night stand, FWB (ifrend with benefit) dalam media sosial Tinder sendiri.

Hookup menurut urbandictionary.com mempunyai arti sebagai berikut "to have any form of intamicy with a member of the prefered sex that you don't consider a significant other. Usually, when said by modern youth it means to make out, and when said by people between the ages of 20 and 35 it generally means to have sex, and if a very old person says it, it probably means to simply spend time with somebody" atau dengan kata lain bahwa hookup merupakan sebuah istilah yang merujuk hubungan intim (seks) dengan seseorang yang tidak dianggap sebagai pasangan sesungguhnya.

Dilansir artikel mengenai "Seks Bebas dalam Praktik Hookup" pada tahun 2017 (Mawa Kresna, http://Tirto.id diunduh 15 September 2019) ditemukan bahwa praktik hookup oleh anak muda sudah dilakukan secara diam-diam. Praktik hookup dengan menggunakan media sosial dating online bukanlah sebuah fenomena baru yang terjadi di Indonesia. Hal ini dikarenakan beberapa dari pengguna akun tersebut berterus terang menuliskan bahwa mereka sedang mencari friend with benefit di deskripsi profil ataupun foto mereka.

Oleh karena itu, Tinder yang merupakan salah satu media sosial dating online terpopuler yang digunakan oleh masyarakat Indonesia (Moch Prima Fauzi dalam http://techno.okezone.com diunduh 15 September 2019) menjadi sarana dalam meningkatnya pergaulan bebas yang ada di kalangan anak muda Indonesia. 
Cervia Ferdiana, Eko Harry Susanto, Sisca Aulia: Penggunaan Media Sosial Tinder Dan Fenomena Pergaulan Bebas Di Indonesia

\section{Metode Penelitian}

Penelitian ini menggunakan pendekatan kualitatif yang berfokus pada fenomena sosial dan pada pemberian suara atas perasaan dan persepsi dan partisipan dibawah studi. Fenomena yang peneliti ambil yakni meningkatnya pergaulan bebas menggunakan media sosial kencan daring. Dalam hal ini, media sosial kencan daring yang diteliti yaitu media sosial kencan daring Tinder.

Peneliti mengumpulkan data menggunakan sumber data primer dan sekunder. Sumber data primer diperoleh melalui wawancara dan observasi partisipan. Wawancara (Susanto, 2018) adalah proses yang berlangsung selama kurang lebih satu jam dengan tujuan mengumpulkan penjelasan atau deskripsi secara dalam dari responden. Wawancara dan observasi partisipan dilakukan peneliti kepada narasumber pengguna media sosial kencan daring Tinder anak muda yang berusia 18-35 tahun.

Dalam pengumpulan data sekunder, peneliti memperoleh data-data berdasarkan sumber-sumber terpercaya untuk dapat melengkapi data dan informasi pada penelitian ini. Peneliti menggunakan data yang bersumber dari buku dan data daring yang digunakan untuk mendapatkan informasi secara mudah dan cepat akan tetapi dapat dipertanggungjawabkan kebenarannya secara akademis (Bungin, 2011)

Untuk mengetahui meningkatnya pergaulan bebas di kalangan anak muda Indonesia, peneliti menanyakan kepada narasumber terkait motivasi pengguna menggunakan media sosial kencan daring Tinder, alasan narasumber memilih media sosial kencan daring Tinder dibanding media sosial kencan daring lainnya, fungsi dari media sosial kencan daring tersebut, serta pergaulan yang ada dalam media sosial kencan daring Tinder.

Dalam melakukan analisis, peneliti juga menggunakan triangulasi sebagai teknik keabsahan data dalam penelitian ini. Menurut Patton triangulasi dilakukan dengan membandingkan data antara hasil wawancara dan hasil pengamatan, lalu membandingkan mengenai pendapat orang berdasarkan situasi penelitian dengan pendapat yang diyakini, serta membandingkan hasil wawancara dengan isi dokumen yang berkaitan (Moleong, 2008).

\section{Hasil Penemuan dan Diskusi}

Media sosial Tinder merupakan dating apps yang dikembangkan oleh InterActiveCorp (IAC) yang merupakan perusahaan media dan internet Amerika Serikat. Sekarang, dating apps tersebut fokus memasarkan aplikasinya untuk masyarakat Indonesia dengan menunjuk agensi iklan Ogilvy sebagai business partner dalam marketing komunikasi periklanan. Aplikasi tersebut diharapkan dapat menjadi sarana dalam mempertemukan jodoh bagi para lajang.

\section{Pergeseran Fungsi Tinder Sebagai Media Pergaulan Bebas}

Dalam penggunaanya sehari-hari, media sosial kencan daring Tinder dapat dikatakan sudah tidak asing lagi bagi kalangan anak muda Indonesia. Akan tetapi seiring berjalannya waktu, media sosial kencan daring tersebut tidak hanya digunakan untuk mencari teman ataupun jodoh saja. Tinder dapat menjadi media pergaulan bebas seperti mencari pasangan one night stand dan friend with benefit dalam penggunaannya. 
Gambar 1. Profil Pengguna Tinder mencari one night stand/FWB

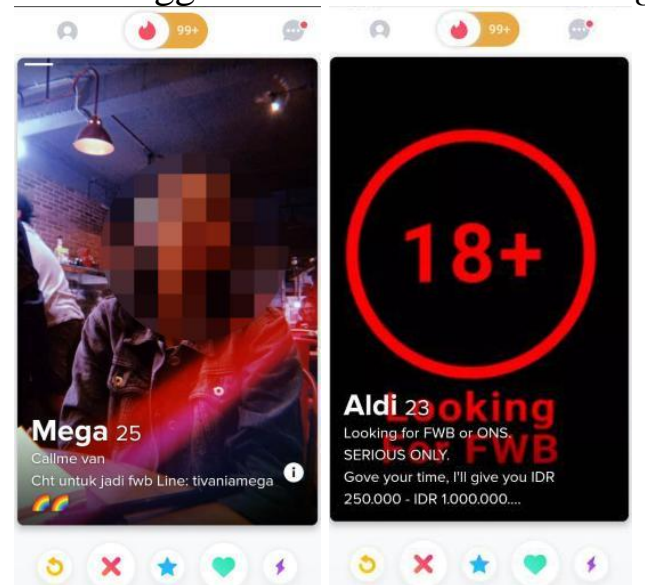

Sumber : aplikasi Tinder

Menurut narasumber Gerry dikarenakan tidak adanya batasan dan peraturan menyebabkan adanya pengguna yang menyalahgunakan media sosial kencan daring tersebut. Berdasarkan 3 fungsi media sosial (Hamid, 2014) yaitu sebagai alat informasi, alat interaksi, serta alat partisipasi. Maka media sosial kencan daring Tinder mengalami penyalahgunaan dan pergeseran fungsi ke arah negatif.

\section{Kemudahan Tinder Sebagai Pencarian Teman One Night Stand}

Pada saat ini, banyak media sosial kencan daring yang tersebar di platform digital android googleplay maupun playstore untuk ios. Dengan adanya media sosial kencan daring memungkinkan seseorang dengan mudah dan praktis dalam bertemu dan berinteraksi antar individu baru tanpa mengenal jarak dan waktu.

Media sosial kencan daring Tinder merupakan salah satu contoh jenis situs jejaring sosial yang populer secara global dan digemari oleh masyarakat anak muda Indonesia pada saat ini.

Kemudahan dan banyaknya pengguna yang sudah memakai media sosial kencan daring ini, memang merupakan daya tarik tersendiri bagi pengguna baru Tinder untuk mencobanya. Namun, kurangnya batasan dan peraturan yang tegas membuat media sosial kencan ini mempunyai disalahgunakan oleh banyak individual.

Gambar 2. Chat Pengguna Tinder mencari one night stand/FWB
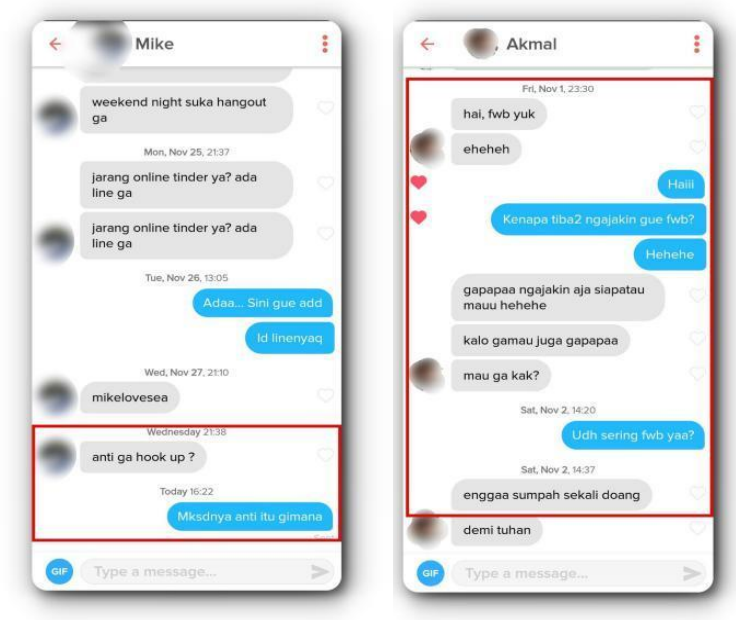

Sumber : Aplikasi Tinde 
Seperti menurut salah satu narasumber yaitu Roy, dirinya memang sedang tidak ingin mempunyai sebuah hubungan serius akan tetapi terkadang membutuhkan seseorang yang dapat diajak bersenang-senang. Dia menggunakan Tinder untuk mencari teman ONS dikarenakan Tinder merupakan media sosial kencan daring yang sudah terkenal, lalu para penggunanya juga mempunyai paras yang elok dan asik untuk diajak berinteraksi.

\section{Media Sosial Tinder Meningkatkan Pergaulan Bebas di Kalangan Anak Muda Indonesia}

Pada umumnya masyarakat Indonesia dikenal sebagai masyarakat yang memegang teguh norma dan nilai-nilai religius yang kuat. Salah satunya adalah tidak melakukan hubungan intim sebelum mempunyai ikatan suci yang sah atau pernikahan. Namun, dengan adanya media sosial yang terhubung dengan seluruh masyarakat dunia. Maka tidak menutup kemungkinan norma dan nilai-nilai tersebut dapat pudar selama melakukan hubungan sosial.

Pergaulan merupakan sebuah proses berkelanjutan yang dilalui antar individu untuk berinteraksi dan mengenal lingkungan sosialnya (Jonathan H. Turner, 1988). Narasumber Andre mengemukakan pendapat dengan menggunakan media sosial kencan daring Tinder dapat mempengaruhi perilaku seseorang secara tidak sadar untuk dapat menyimbangkan komunikasi antar individu tersebut.

Dapat dikatakan bahwa terjadinya peningkatan pergaulan bebas di kalangan anak muda Indonesia dengan penggunaan media sosial kencan daring Tinder dikarenakan beberapa faktor. Pertama, pengguna yang mempunyai pemahaman dan pola pikir terbuka terhadap hal tersebut, kedua, rasa keingintahuan yang tinggi terhadap hal yang belum pernah dirasakan, dan ketiga, karena faktor lingkungan yang mendukung individu tersebut.

\section{Simpulan}

Pada saat ini, media sosial kencan daring Tinder mengalami pergeseran fungsi karena adanya pengguna yang menyalahgunakan media sosial tersebut sebagai media untuk pergaulan bebas seperti one night stand dan friend with benefit. Pemilihan Tinder sebagai media untuk mencari teman bersenang-senang semalam dikarenakan karena media sosial kencan daring tersebut sudah terkenal di semua kalangan masyarakat secara global, serta banyaknya pengguna yang memiliki paras elok dan menawan menjadi salah satu faktor para penggunanya untuk menggunakan media sosial kencan daring Tinder dibandingkan media sosial kencan daring lainnya. Selain itu, banyak pengguna yang sudah memiliki pemahaman dan pola pikir yang terbuka maka Tinder merupakan media yang dianggap tepat untuk mencari teman one night stand.

Peningkatan pergaulan bebas yang terdapat di kalangan anak muda Indonesia dapat disebabkan oleh beberapa faktor. Seperti adanya faktor keingintahuan yang tinggi terhadap hal yang belum pernah dirasakan orang tersebut, lalu adanya faktor dari lingkungan sosial individual yang membuat anak muda dapat masuk dalam pergaulan bebas. 


\section{Ucapan Terima Kasih}

Pada kesempatan ini, peneliti mengucapkan terima kasih kepada seluruh pihak yang telah membantu peneliti selama proses dan penyelesaian dalam penelitian dan penulisan artikel ini.

\section{Daftar Pustaka}

Abraham Herdyanto. (2019).7 Aplikasi Kencan yang Bisa Kamu Gunakan. September 12,2019 https://www.idntimes.com/tech/gadget/abrahamherdyanto/rekomendasi-dating-apps-terbaik

Bungin, Burhan. (2011). Penelitian Kualitatif. Jakarta: Kencana Prenada Media Group Hamid, Usman. (2014). Dinamo: Digital National Movement. Yogyakarta:PT. Bentang Pustaka

Ihsan, Masykur. (2016). Pengaruh Terpaan Media Internet Dan Pola Pergaulan Terhadap Karakter Peserta Didik. Hal 106

Kiki Oktaviani. (2015). Tak Selalu Gagal, Ini Kisah Sukses Cari Jodoh Lewat Tinder. September 15 2019 https://wolipop.detik.com/love/d-2805765/tak-selalugagal-ini-kisah-sukses-cari-jodoh-lewat-Tinder

Lexy, J Moleong. (2008) Metodologi Penelitian Kualitatif, Bandung: PT Remaja Rosdakarya.

Mark Jansen.(2019). The best dating apps for 2019. Desember 12, 2019. https://www.digitaltrends.com/mobile/best-dating-apps/

Mawa Kresna. (2017). Aplikasi Kencan: Cari Jodoh atau Teman Bobo?. September 15,2019 https://tirto.id/aplikasi-kencan-cari-jodoh-atau-teman-bobo-ctrR

Mawa Kresna. (2017). Seks Bebas dalam Praktik Hookup. September 15 ,2019 https://tirto.id/seks-bebas-dalam-praktik-hookup-crPy

Moch Prima Fauzi. (2017). Pengguna Aplikasi Kencan Tertinggi di Rusia, Indonesia Nomor Berapa?. September 15 https://techno.okezone.com/read/2017/02/16/207/1620005/penggunaaplikasi-kencan-tertinggi-di-rusia-indonesia-nomor-berapa

Nick Bilton. (2014). Tinder, the Fast-Growing Dating App, Taps an Age-Old Truth. September 12 ,2019 https://www.nytimes.com/2014/10/30/fashion/Tinderthe-fast-growing-dating-app-taps-an-age-old-truth.html

Susanto, Eko Harry. (2018). Komunikasi Manusia: Teori dan Praktik Dalam Penyampaian Gagasan. Jakarta: Penerbit Mitra Wacana Media

Tim Editor. (2019). 9 Aplikasi Kencan Yang Populer Di Kalangan Pemburu Jodoh. September 12 2019 https://kumparan.com/@kumparanstyle/9-aplikasikencan-online-yang-populer-di-kalangan-pemburu-jodoh1546672121249302476

Tim Editor. (2019). Kisah 3 Perempuan Yang Sukses Menikah Dari Kencan Online. September 15 2019 https://kumparan.com/@kumparanstyle/it-s-a-matchkisah-3-perempuan-yang-sukses-menikah-dari-kencan-online1546656818966760062

Turner, Jonathan H. (1988). A Theory of Social Interaction. Stanford: Stanford University Press

Yougov Staff. (2017). Sepertiga orang Indonesia pernah menggunakan layanan $\begin{array}{llll}\text { kencan } & \text { online. } & \text { September } & 15\end{array}$ https://id.yougov.com/id/news/2017/11/23/internet-dating/ 
Cervia Ferdiana, Eko Harry Susanto, Sisca Aulia: Penggunaan Media Sosial Tinder Dan Fenomena Pergaulan Bebas Di Indonesia

Yourdan. (2016). Hari Pertama Kenalan di Tinder, Hari Kedua Dibelikan Mobil, Hari Ketujuh Nikah! Senangnya Rey Utami. September 15 ,2019 https://www.hipwee.com/hiburan/dikasih-mobil-di-hari-kedua-berkenalanlalu-dilamar-di-hari-keenam-senangnya-presenter-ini/ 